\title{
Invited review: Modeling within-herd transmission of Mycobacterium avium subspecies paratuberculosis in dairy cattle: A review
}

\author{
C. Marcé, ${ }^{*} \dagger^{1}$ P. Ezanno, ${ }^{*}$ M. F. Weber, $\ddagger$ H. Seegers, ${ }^{*}$ D. U. Pfeiffer, $\dagger$ and C. Fourichon ${ }^{*}$ \\ *INRA, ONIRIS, UMR1300 Bioagression, Epidémiologie et Analyse de Risque, BP 40706, F-44307 Nantes, France \\ †Veterinary Epidemiology and Public Health Group, Royal Veterinary College, University of London, Hatfield AL9 7TA, Hertfordshire, \\ United Kingdom \\ ‡GD Animal Health Service, PO Box 9, 7400 AA Deventer, the Netherlands
}

\section{ABSTRACT}

Epidemiological models have been developed to test hypotheses on Mycobacterium avium ssp. paratuberculosis (Map) transmission in a herd, and to compare different paratuberculosis control strategies and alternatives for certification-and-surveillance schemes. The models are simplified representations of existing biological processes tailored to the questions they are intended to answer. Such models depend on available knowledge about the underlying processes, notably in relation to pathogen transmission. All decisions relating to integration of specific aspects of the herd structure and transmission mechanisms as well as modeling objective will influence model behavior and simulation results. This paper examines assumptions on pathogen transmission and risk mitigation represented in 8 epidemiological models of within-herd Map transmission in dairy cattle. We describe available models' structure and examine them in the context of current knowledge about host infection and pathogen transmission pathways. We investigate how population structure and herd management are modeled with regard to their influence on contact structure and pathogen transmission. We show that assumptions about routes of transmission and their contribution within a herd vary greatly among models. Gaps of knowledge that are pivotal to defining transmission equations and parameters, such as variation of susceptibility with age and variability of pattern of shedding, are identified. Quantitative estimates of this incomplete information should be targeted by future research. Existing models could be improved by considering indirect transmission via the environment taking account of Map survival and contact structure between animals in a herd, and by including calf-to-calf transmission, which has recently been proven as being important.

Received February 4, 2010.

Accepted June 7, 2010.

${ }^{1}$ Corresponding author: clara.marce@oniris-nantes.fr
Key words: Mycobacterium avium ssp. paratuberculosis, dynamic model, transmission, review

\section{INTRODUCTION}

Paratuberculosis is of significant economic importance for dairy producers as it results in a decrease in milk production, mortality, or premature culling of sick cattle, and reduction in slaughter value of clinically affected cattle in affected dairy herds (Benedictus et al., 1987; Johnson-Ifearulundu and Kaneene, 1997). Furthermore, the zoonotic importance of Mycobacterium avium ssp. paratuberculosis (Map) in the pathogenesis of Crohn's disease is still controversial (European Commission, 2000; Frank, 2008; Shafran and Burgunder, 2008). These factors justify the development of effective and economically viable control programs against paratuberculosis. However, no treatment is currently available. Until now, certification and control programs implemented in several countries have had only limited success. A better understanding of Map transmission is required to implement appropriate measures for protecting susceptible cattle.

Field studies on Map transmission are difficult because infection occurs mainly in young stock and clinical signs arise after a long incubation period ( 1 to $\geq 15 \mathrm{yr}$ ). Such studies are further complicated by the low and varying sensitivity of diagnostic tests. Modeling thus appears to be an appropriate tool to study paratuberculosis. Indeed, epidemiological models can be used to identify the main factors influencing pathogen transmission within a herd, and to assess ex ante control strategies of Map spread. Relevance of model outputs depends on the modeling approach used, the assumptions made (including parameterization) and the level of simplification of the biological mechanisms modeled.

For Map transmission, several models have been developed (1) to investigate Map spread in a herd and its economic consequences (van Roermund et al., 2002; Pouillot et al., 2004); (2) to test transmission hypotheses such as representing indirect transmission 
via the environment (Humphry et al., 2006) or considering transiently shedding young animals (Mitchell et al., 2008); (3) to compare strategies for control of Map spread in infected herds (Collins and Morgan, 1991b; Kudahl et al., 2007a; Lu et al., 2008) or in populations with infected and noninfected herds (Groenendaal et al., 2002, 2003; van Roermund et al., 2002); and (4) to compare certification-and-surveillance programs aimed at low-risk pathogen transmission associated with cattle trade (Kalis et al., 2004; Weber et al., 2004; Ezanno et al., 2005) or at quality assurance of dairy products (van Roermund et al., 2002; Groenendaal and Zagmutt, 2008; Weber et al., 2008).

Our objective is to describe and discuss assumptions used in Map transmission models within dairy cattle herds with particular emphasis on representation of infection status, routes of transmission, and exposure at the herd level. Current scientific knowledge about Map transmission is summarized and then used to evaluate the validity of the models described in the scientific literature. Assumptions dealing with infection at the host level, transmission from infected to susceptible cattle, and population structure influencing transmission in a dairy herd are discussed in particular. As a conclusion, we provide recommendations for future modeling studies or for improvement of existing models.

\section{SELECTION OF RELEVANT PAPERS}

Peer-reviewed papers and conference proceedings dealing with Map transmission models in dairy cattle were systematically selected using electronic search engines. The search was conducted using the following scientific literature electronic databases: $\mathrm{CAB}(\mathrm{CAB}$ International, Oxon, UK), Medline (National Library of Medicine, Rockville Pike, MD), ISI Web of Knowledge (Thomson Reuters, New York, NY), and one conference proceedings website, the International Colloquiums on Paratuberculosis (http://pubs.paratuberculosis.org/). The search was first conducted on March 30, 2008, and repeated regularly until February 4, 2010. Studies from conference proceedings were included if they had not been published in peer-reviewed journals. Search terms used were "paratub*" and "model*" occurring in titles, abstracts, subject headings, keywords, or descriptors. Only articles written in the English language and describing models that aimed at representing the transmission of Map within cattle herds were considered. Papers using models described previously in other peer-reviewed articles were not retained unless they represented novel approaches to the study of Map transmission. Consequently, economic models that aimed at assessing the cost of the disease or cost of different control programs without providing any in- formation on the dynamics of Map spread or without relying on Map transmission modeling were excluded (Groenendaal et al., 2003; Kalis et al., 2004; Weber et al., 2004; Dorshorst et al., 2006; Tavornpanich et al., 2008; Weber et al., 2008).

Based on the above criteria, 6 models were selected from peer-reviewed papers (Collins and Morgan, 1991b; Groenendaal et al., 2002; Pouillot et al., 2004; Humphry et al., 2006; Kudahl et al., 2007a; Mitchell et al., 2008) and 2 from conference proceedings (van Roermund et al., 2002, 2005) (Table 1).

All models represent Map transmission within a dairy herd except one that does so within a beef herd (Humphry et al., 2006). This beef model has been kept in our review because specific assumptions on transmission are used that may be relevant for models in dairy cattle.

\section{TECHNICAL CHARACTERISTICS OF THE SELECTED MODELS}

The selected models differed not only with respect to the biological hypotheses on which they are based, but also in relation to the technical characteristics of the models, such as discrete-time (appreciable period of time such as a day or a year) versus continuous-time or deterministic versus stochastic implementation (Table 1). Hypotheses on the model system such as type of herd, herd structure, and routes of pathogen introduction are discussed later in this review.

Four models are discrete-time stochastic models that use random sampling from input parameter distributions or binomial distribution of event probability to represent variability in Map transmission (models 2, 4, 6, and 7). Three models are continuous-time deterministic models (models 3, 4, and 5), and one is a discrete-time deterministic model (model 8); links between references and model numbers are given in all tables.

Representation of biological mechanisms can be more precise in models based on a short time step or assuming a continuous time process than in models based on a longer time step, because processes operating at a time scale shorter than the time step cannot be considered. In the selected models, for example, choosing a time step of 6 mo will not allow testing different lengths of the susceptible period (other than a multiple of 6 mo), testing different lengths of the shedding period, or differentiating infection during the first weeks after birth from infection after weaning. However, choosing a longer time step is more convenient when studying long-term effects or year-round management, because the model then becomes computationally more tractable given the reduced parameter set. 
Table 1. Modeling options of 8 Mycobacterium avium paratuberculosis (Map) transmission models in cattle herds

\begin{tabular}{|c|c|c|c|c|c|c|}
\hline \multicolumn{2}{|c|}{ Model/reference } & \multirow{2}{*}{$\begin{array}{l}\text { Type } \\
\text { of herd } \\
\text { Dairy }\end{array}$} & \multirow{2}{*}{$\begin{array}{l}\begin{array}{l}\text { Effect } \\
\text { of chance }\end{array} \\
\text { Deterministic }\end{array}$} & \multirow{2}{*}{$\begin{array}{l}\text { Treatment } \\
\text { of time } \\
\text { (interval) }\end{array}$} & \multirow{2}{*}{$\begin{array}{c}\begin{array}{c}\text { Length } \\
\text { of simulation } \\
(\mathrm{yr})\end{array} \\
50\end{array}$} & \multirow{2}{*}{$\begin{array}{l}\text { Output } \\
\text { Prevalence of infected animals }\end{array}$} \\
\hline 1 & $\begin{array}{l}\text { (Collins and } \\
\text { Morgan, 1991b) }\end{array}$ & & & & & \\
\hline 2 & $\left(\right.$ Groenendaal et al., 2002) ${ }^{1}$ & Dairy & Stochastic & Discrete (6 mo) & 20 & $\begin{array}{l}\text { Distribution of within-herd prevalence of infection; } \\
\text { proportion of herds in various statuses of } \\
\text { certification-and-surveillance programs (Weber et } \\
\text { al., 2004, 2008); distribution of the concentration } \\
\text { of Map in bulk milk (Weber et al., 2008) }\end{array}$ \\
\hline 3 & (van Roermund et al., 2002) & Dairy & Deterministic & Continuous model & Not given & $\begin{array}{l}\mathrm{R}_{\mathrm{h}}=\text { number of newly infected farms by one } \\
\text { infected farm in a naïve metapopulation }\end{array}$ \\
\hline 4 & (Pouillot et al., 2004) & Dairy and beef & $\begin{array}{l}\text { One stochastic and } \\
\text { one deterministic }\end{array}$ & $\begin{array}{l}\text { Discrete }(1 \mathrm{yr}) \text { for } \\
\text { the stochastic model; } \\
\text { continuous for the } \\
\text { state transition model }\end{array}$ & 30 & $\begin{array}{l}\text { Yearly incidence rate; yearly prevalence } \\
\text { of infected animals; cumulated yearly } \\
\text { disease extinction probability }\end{array}$ \\
\hline 5 & (van Roermund et al., 2005) & Dairy & Deterministic & Continuous model & 10 & $\begin{array}{l}\text { Prevalence in infected herds; average number } \\
\text { of Map bacteria in bulk milk; number of } \\
\text { infected and free dairy herds in the country; } \\
\text { number of herds in various status of a } \\
\text { certification-and-surveillance program }\end{array}$ \\
\hline 6 & (Humphry et al., 2006) & Beef & Stochastic & Discrete $(6 \mathrm{mo})$ & Not given & Number of subclinical and clinical animals \\
\hline 7 & (Kudahl et al., 2007a) & Dairy & Stochastic & Discrete (1 wk) & 10 & $\begin{array}{l}\text { Number of animals in each state; } \\
\text { prevalence of infected animals }\end{array}$ \\
\hline 8 & (Mitchell et al., 2008) & Dairy & Deterministic & Discrete $(1 \mathrm{mo})$ & 25 & Prevalence of infected animals \\
\hline
\end{tabular}


1 year of age

A)

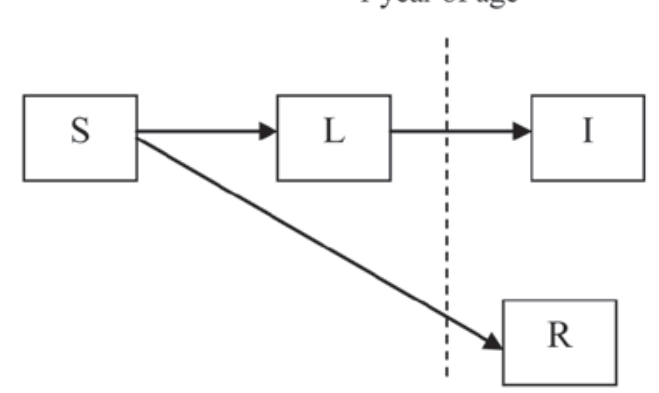

B)

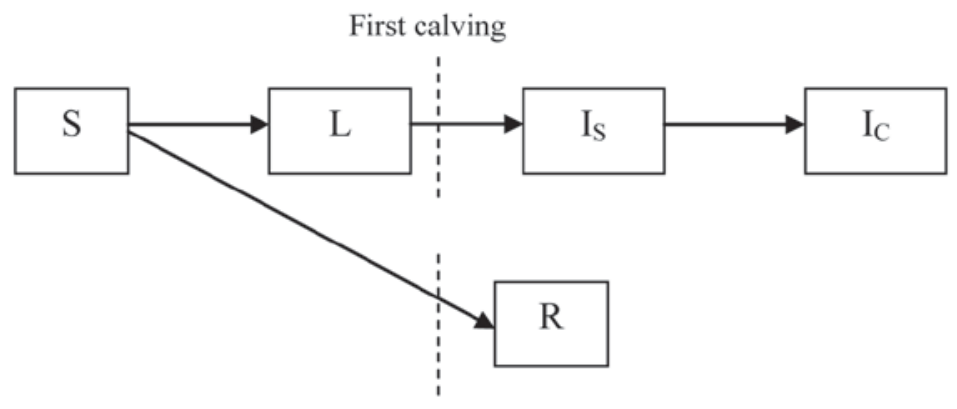

1 year of age

No age limit

First calving

2 years of age

C)

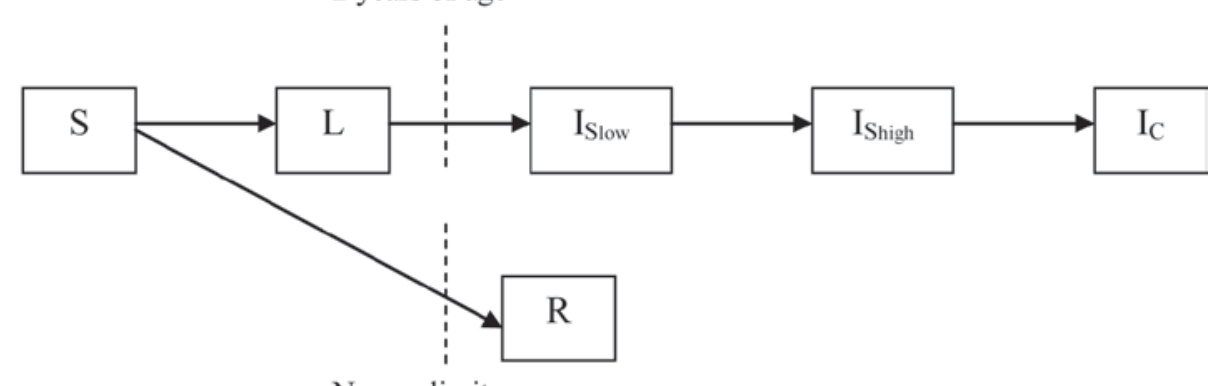

No age limit

0.5 year of age

1 year of age

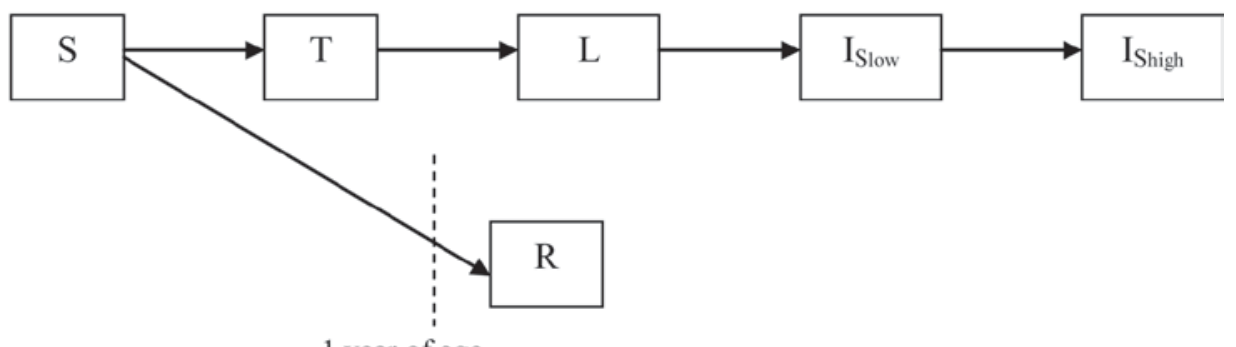

1 year of age

Figure 1. Graphical representation of health statuses and transitions in Mycobacterium avium paratuberculosis transmission model of A) Collins and Morgan (1991b); B) Pouillot et al. (2004); C) Kudahl et al. (2007a), Groenendaal et al. (2002), Humphry et al. (2006), and van Roermund et al. (2002, 2005); and D) Mitchell et al. (2008). S = susceptible; $\mathrm{T}=$ transiently infectious; $\mathrm{L}=$ latent; I = infected; $\mathrm{I}_{\mathrm{S}}=$ subclinically infected; $\mathrm{I}_{\text {Slow }}=$ subclinically infected low shedder; $\mathrm{I}_{\text {Shigh }}=$ subclinically infected high shedder; $\mathrm{I}_{\mathrm{C}}=$ clinically affected; $\mathrm{R}=$ resistant; ------ $=$ minimal age before entering the following status. 
Deterministic models represent the mean behavior of the system modeled. Such a representation is generally suited for a large population. In contrast, stochastic models take into account variability in event occurrence and therefore allow representation of likely variation within small populations. Several replications are indeed implemented based on the same inputs and initial conditions to assess the distribution of model outputs besides their average.

\section{MODELING THE INFECTION IN THE HOST}

\section{Host Susceptibility}

Mycobacterium avium ssp. paratuberculosis infection is known to occur mainly in newborn calves (Hagan, 1938). It is generally acknowledged that calves can become infected until 1 yr of age, especially during the first weeks after birth. Resistance to infection increases until 1 yr, especially after 1 to 4 mo of age (Taylor, 1953; Windsor and Whittington, 2010). After 1 yr, cattle are considered resistant except when exposed to repeated infection with large amounts of bacteria (Doyle, 1953; Taylor, 1953; Larsen et al., 1975).

In the models, most researchers assume that susceptibility to $M a p$ is age-related and define a maximum age of infection at 0.5 (model 3) or 1 yr of age (models 1 , 2, 4, 5, 7, and 8) (Figure 1). Cattle that do not become infected by the chosen age limit are assumed resistant (Table 2). Only one model assumes that adults can become infected but with a much lower probability (model 6 ; Figure 1). In young stock, susceptibility to Map either remains constant (models $1,3,4$, and 8 ) or varies with age (models 2, 6, and 7). Model 2 compares 2 different approaches for modeling the decrease of susceptibility with age (model 2; http://cahpwww.vet.upenn.edu/ field/johne_report.pdf). The true prevalence is higher when a linear decrease of the susceptibility of young calves to paratuberculosis is assumed than when an exponential decrease is assumed. However, the difference between the true prevalence under both assumptions is small. Assuming an exponential decrease necessitates defining only 1 parameter, whereas assuming a linear decrease necessitates defining 2 parameters. It is thus preferable to choose the simplest representation: the exponential one.

Several experimental studies indicate genetic variation of susceptibility among cows (Koets et al., 2000; Mortensen et al., 2004; Gonda et al., 2006, 2007). This, so far, has not been taken into account in Map transmission models. It is thus not possible to consider selectively culling the most susceptible calves based on genetic markers, a method that could be an earlier and less expensive control measure than a test-and-cull option.
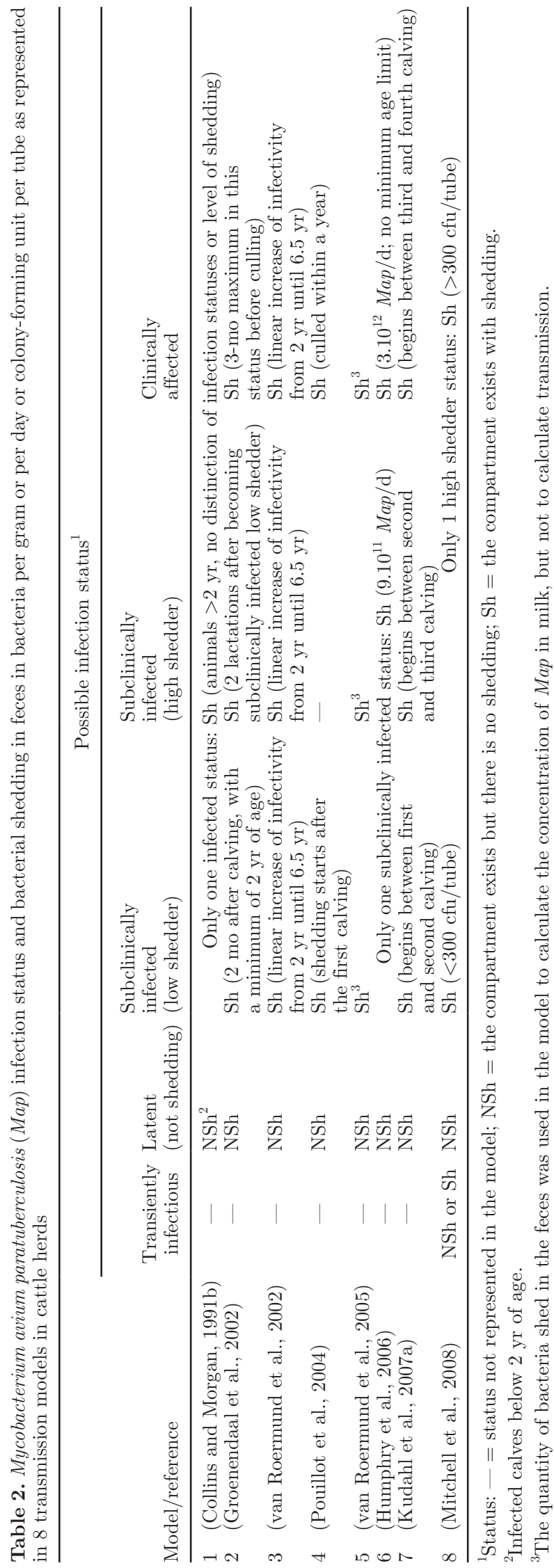

Journal of Dairy Science Vol. 93 No. 10, 2010 


\section{Development of the Disease Within the Host and Map Shedding}

Infection Stages. Following infection, calves are able to shed the bacteria without any clinical signs (Bolton et al., 2005; Weber et al., 2006; van Roermund et al., 2007). The incubation period can last from $<2$ to $>10$ yr (van Roermund et al., 2007; Weber et al., 2009), during which time adult cattle may or may not shed bacteria in their feces (at different levels of shedding) (Chiodini et al., 1984; Whitlock and Buergelt, 1996; Crossley et al., 2005). Later, clinical signs are characterized by losses of milk production, significant weight loss, and diarrhea (Smythe, 1950, Clarke, 1997), leading to death if cattle are not culled. During the clinical stage of pathogenesis, massive numbers of bacteria are excreted in the feces.

In the models, infection stages taken into account differ (Figure 1) and are associated with different levels of shedding. The simplest representation considers latently infected cattle (not shedding) versus infected cattle shedding all the same amount of bacteria (model 1; Figure 1A). In contrast, the most recently published models define 6 infection stages (models 5, 6, 7, and 8; Figure 1D). This evolution in terms of number of infection stages considered is mainly associated with the progress made in development of new Map knowledge. However, 2 models do not consider explicitly clinically affected animals, although they play a specific role in terms of transmission (higher load of Map shed, higher risk of in utero transmission, higher probability of being culled; models 1 and 8). In all models, the individual progresses through the various stages of the infection-and-disease process with increasing age. However, within a specific stage of the infection-and-disease process, shedding is considered independent of age. So, if an animal sheds Map and if an appropriate test is used, detection of an infected animal will occur with a constant probability. In contrast, in the field, shedding appears to vary in time for an infected animal; a test performed one day can miss an infected animal that was possibly shedding the day before and could possibly shed Map the day after. The mean probability to cull an infected animal potentially shedding should be equivalent in the model and in the field. However, the variability in the field can be expected to be more important. Simulated scenarios are probably more homogeneous in terms of the probability of being culled, with less extreme values. Although model 8 considers a uniform and deterministic disease progression with cattle progressing through the same disease stages regardless of the age of infection, model 1 considers that once infected, all calves become infectious at $2 \mathrm{yr}$ of age. Other authors assume that progress to the next in- fectious stage and increase in infectivity depend on the age of animals (models $3,4,5,6$, and 7 ) or the route of infection (in utero, at birth, through colostrum/milk, through feces ingestion approximated by the number of contacts between animals; model 2). Animals of the same age can shed different amounts of Map only for this last option, and the route of infection then has an effect on test-and-cull efficacy for every animal. The incubation period considered in the models varies between models (with a range of 2 to $22 \mathrm{yr}$, generally around $5 \mathrm{yr}$ ). If the delay before becoming clinically affected is long, the prevalence is expected to increase as direct detection (clinical signs) occurs less often. However, the incidence could decrease because there are fewer animals shedding a very high amount of Map in feces. The consequence on the achievement of persistence is not known. The overall effect of the length of the incubation period is difficult to predict without comparing the different situations by simulation with the same model, everything else being constant.

Factors Influencing the Course of Infection. There is little information available in the scientific literature on factors influencing the course of infection. Some studies indicate that age at infection is a major determinant of occurrence of clinical signs and of shedding of detectable levels of Map: the younger that cattle are when infected, the quicker they develop clinical signs (Rankin, 1961; Whitlock and Buergelt, 1996) and the more likely they are to shed detectable levels of Map (Kostoulas et al., 2010). In experimental infection, a relationship between the dose given to the animals and occurrence of lesions and clinical signs was demonstrated (Begg and Whittington, 2008), with larger doses resulting in earlier disease development. It is also acknowledged that factors such as stress may influence the development of the disease (Chiodini et al., 1984).

These characteristics have been integrated differently in the models studied (Table 2, Figure 1). Only model 2 considers age at infection as influencing the course of infection (the earlier the infection occurs, the quicker the progression of the disease), whereas the others do not. Young animals could thus shed large doses of Map in model 2. This may influence the effect of control measures. More biological studies are necessary to assess whether this assumption is realistic. The number of infectious animals characterizes exposure and thus the probability of becoming infected, but not the evolution from one status to the next when infected (models 4, 5, 6 , and 8). Stressors such as calving or change of feed are taken into account in one model as factors influencing disease progression (model 7). The underlying assumption is that stress accelerates the development of clinical signs for infected animals. In that model, animals can become clinically affected and thus be detected earlier. 
Table 3. Probability of infection and underlying assumptions used to model Mycobacterium avium paratuberculosis horizontal transmission in 8 models (intrauterine infection, infection at birth, and infection through milk and colostrum excluded)

\begin{tabular}{|c|c|c|c|c|c|}
\hline \multicolumn{2}{|c|}{ Model/reference } & $\begin{array}{l}\text { Probability } \\
\text { of infection }^{1}\end{array}$ & \multirow{2}{*}{$\begin{array}{l}\text { Categories of animals } \\
\text { to which susceptible } \\
\text { animals } \\
\text { are exposed } \\
\text { Number of infected } \\
\text { adults }\left(I_{a}\right)\end{array}$} & \multirow{2}{*}{$\begin{array}{l}\text { Type of contact } \\
\text { Direct contact between } \\
\text { calves and adults }\end{array}$} & \multirow{2}{*}{$\begin{array}{l}\text { Probability } \\
\text { of transmission } \\
\text { if infectious contact } \\
\text { Constant }=1\end{array}$} \\
\hline 1 & (Collins and Morgan, 1991b) & $1-\left(1-\frac{k}{N_{c}}\right)^{I_{a}}$ & & & \\
\hline 2 and 5 & $\begin{array}{l}\text { (Groenendaal et al., 2002; } \\
\text { van Roermund et al., 2005) }\end{array}$ & $1-\left(1-\frac{k(a g e)}{N_{a}} s(a g e)\right)^{I_{a}}$ & $\begin{array}{l}\text { Number of infected } \\
\text { adults in the } \\
\text { last } 6 \text { mo }\left(I_{a}\right)\end{array}$ & $\begin{array}{l}\text { Direct contact between } \\
\text { calves and adults }\end{array}$ & $\begin{array}{l}\text { Varies with calf susceptibility, which } \\
\text { depends on age; } I_{a}=\text { weighted sum to } \\
\text { take account of the shorter shedding } \\
\text { of lowly infectious animals }\end{array}$ \\
\hline 3 & (van Roermund et al., 2002) & $\int_{a g e} \beta(a g e) \frac{I_{a g e}}{N}$ & $\begin{array}{l}\text { Proportion of infected } \\
\text { animals per age }\end{array}$ & $\begin{array}{l}\text { Direct contact between } \\
\text { calves and adults }\end{array}$ & $\begin{array}{l}\text { Frequency-dependent, varies with } \\
\text { infectivity, which depends on age }\end{array}$ \\
\hline 4 & (Pouillot et al., 2004) & $1-\prod_{i}\left(1-\tau_{(i)}\right)^{I_{i}}$ & $\begin{array}{l}\text { Number of infected } \\
\text { cows }(I)\end{array}$ & $\begin{array}{l}\text { Direct contact between } \\
\text { calves and adults }\end{array}$ & Varies with adults infectious statuses \\
\hline 6 & (Humphry et al., 2006) & $1-[1-p(\text { age })]^{b\left(I_{i}, t\right)}$ & $\begin{array}{l}\text { Bacterial density in } \\
\text { the environment }(b)\end{array}$ & $\begin{array}{l}\text { Indirect contact via } \\
\text { the environment }\end{array}$ & Varies with age of susceptible animals \\
\hline 7 & (Kudahl et al., 2007a) $^{3}$ & $1-\left(1-\frac{k(a g e)}{N_{a}} s(\right.$ age $\left.) \rho\right)$ & $\begin{array}{l}\text { Number of infectious } \\
\text { cows }\left(I_{a}\right)\end{array}$ & $\begin{array}{l}\text { Direct contact between } \\
\text { calves and adults }\end{array}$ & $\begin{array}{l}\text { Varies with calf susceptibility, } \\
\text { which depends on age }\end{array}$ \\
\hline 8 & (Mitchell et al., 2008) & $\sum_{i} \beta(i) \frac{I_{i}}{N}$ & $\begin{array}{l}\text { Proportion of } \\
\text { infected animals per } \\
\text { infectious status }\end{array}$ & $\begin{array}{l}\text { Direct contact between } \\
\text { calves and adults, } \\
\text { or among calves }\end{array}$ & $\begin{array}{l}\text { Frequency-dependent, varies with } \\
\text { adults infectious status }\end{array}$ \\
\hline
\end{tabular}

of factor depending on calves' age; $s=$ calf susceptibility; $\tau_{i}=$ pathogen transmission probability related to adult infectious status $i$; $t=$ time

$\stackrel{2}{\stackrel{D}{F} \text {. }} \quad{ }^{2}$ For more details on this model, see the report found on http://cahpwww.vet.upenn.edu/field/johne_report.pdf.

An error in the formulation of the probability of infection in the original paper has been detected; the formula is here corrected and validated by the authors. 
Table 4. Transmission pathways of Mycobacterium avium paratuberculosis considered in 8 transmission models in cattle herds ${ }^{1}$

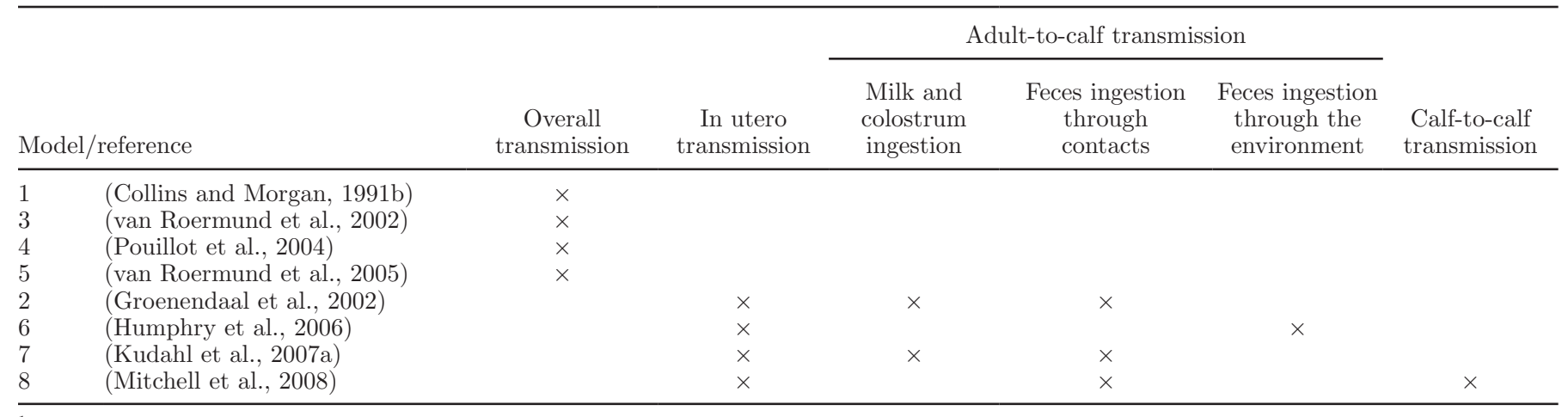

${ }^{1} \times=$ included in the model; empty cell $=$ not included in the model.

Not considering such factors implies that only a mean behavior is studied, with all cows being exposed to the same stressors.

Shedding Characteristics. Shedding of Map mainly occurs in feces, but Map is also found in colostrum and milk of subclinically or clinically infected cows (Taylor et al., 1981; Sweeney et al., 1992b; Streeter et al., 1995). Several studies have shown inter- and intra-individual variability in the number of excreted bacteria (Whitlock et al., 2000; Crossley et al., 2005). Fecal shedding of Map has also been described in young stock (Bolton et al., 2005; Antognoli et al., 2007; van Roermund et al., 2007) but culture data indicate that calves do not shed as frequently or as much as adults (Rankin, 1961; Nielsen and Ersboll, 2006; van Roermund et al., 2007). High fecal shedders are more likely to shed the bacteria in their colostrum and milk than are low fecal shedders (Sweeney et al., 1992a; Streeter et al., 1995). Furthermore, high fecal shedders are more likely to be detected with currently available tests.

In the models, cattle are usually categorized depending on their level of shedding (Table 2). Levels of shedding influence the infectiousness (models 2, 3, 4, 7, and 8 ) either because the probability of infection is different depending on health status, or because the number of infected cattle is balanced by allocating to the less infectious cattle a shorter time period of Map shedding (in the same quantity) than to high shedders (model 2 ; Table 3). However, little information is generally available on the quantity of bacteria shed by animals depending on their infection stage (Table 2). Only one model does not consider that levels of shedding influence the probability of transmission (model 1) because it considers only one level of shedding. This simplification does not allow a study of control measures targeting animals that shed the highest levels of Map. Only one model assumes that calves are able to shed the bacteria (model 8). In that model, shedding is substantially lower for calves than for low-shedding adults. Studying between-calf Map transmission is possible here as is evaluating the contribution of the different routes of transmission and studying control measures specifically targeting young shedding cattle.

Level of shedding also influences management and production parameters. Higher levels of shedding are associated with a higher probability of being culled if test-and-cull is used for control. Models distinguishing several levels of shedding allocate sensitivity and specificity of diagnostic tests depending on these levels of shedding. Finally, models aiming at quantifying Map in bulk tank milk as an output (bacteria per liter) also rely on accurate representation of levels of shedding in both milk and feces (van Roermund et al., 2005; Weber et al., 2008).

\section{MODELING THE TRANSMISSION OF THE PATHOGEN}

Vertical or direct in utero transmission from dam to calf has been reported (Whittington and Windsor, 2009). In a meta-analysis, Whittington and Windsor (2009) estimated that 9\% of fetuses born from subclinically infected cows and 39\% from clinically affected cows were infected with Map. Other potential sources of vertical transmission could be semen or embryo transplants but these routes seem to be rare (Kruip et al., 2003).

Horizontal transmission is due to ingestion of Map from contaminated sources, especially from feces (Chiodini et al., 1984), but also from milk and colostrum. In fact, Map is shed directly in milk and colostrum and fecal contamination of milk and colostrum occurs (Nauta and van der Giessen, 1998). For a long time it was thought that transmission occurs only from adults to calves, but calf-to-calf transmission has been reported recently, albeit at a lower level than adult-to-calf transmission (van Roermund et al., 2007). It seems that Map is unable to multiply in the environment (Whittington 
et al., 2004), but it can survive in the environment for several months and in feces for up to $55 \mathrm{wk}$ (Lovell et al., 1994; Whittington et al., 2004, 2005). Soil desiccation and exposure to direct sunlight shorten survival (Larsen et al., 1956; Whittington et al., 2004).

In the reviewed models, the number of transmission pathways considered varies (Table 4). Out of 5 models explicitly representing fecal-oral transmission, 4 assume direct contacts between susceptible and infected animals (models 1, 2, 7, and 8; Table 3). A further assumption in these models is that animals are raised together, which is not always correct. Furthermore, it is difficult to estimate the frequency of contact and the probability of infection given contact. Two types of force of infection (transmission rate per susceptible animal) are used: density- and frequency-dependent (Table 3). In the first case (density-dependent), the number of cases is usually considered, whereas in the latter (frequency-dependent), the proportion of infected cattle in the population is considered (Begon et al., 2002; Hoch et al., 2008). The consequence of such a choice is discussed below when the impact of herd size is addressed. A link between the extent of animal confinement and pathogen transmission is considered in model 4: transmission is more likely if disease onset occurs during the calving period, assumed to always be indoors in this model, than if it occurs when animals are kept on pasture.

The only model that does not consider fecal-oral transmission by direct contact explicitly includes indirect transmission via the environment by taking into account the density of Map and its survival in the environment (model 6). A constant survival rate of the bacteria leads to an exponential decay model. Susceptible animals are exposed to a specific bacterial density present in the environment, these bacteria being shed by infectious animals that are or were present. Whatever their age, cattle are exposed to the same contact rate with Map within a specific environment (homogeneous contacts). Infectious areas are larger outdoors and are consequently associated with a lower exposure.

Survival of Map in the environment should be considered to account for the potential delay between shedding and exposure to Map that can be followed by infection, which may change the predictions when modeling different control options. As Map transmission mainly occurs via ingestion of feces, the probability that a contact involves a shedding animal is likely to underestimate transmission because transmission can occur even if no shedding animals are present in the herd as the bacteria may persist for a long time in the environment.

Calf-to-calf transmission is generally not accounted for, except in model 8. In this model, the sensitivity of transmission dynamics in the herd to calves shedding is explored. Accounting for age-dependent contacts, calfto-calf transmission has been shown to be required for Map to persist in the herd (model 8). Such a result is in agreement with observations from a field study, which were better explained by a statistical model when including calf-to-calf transmission (van Roermund and de Jong, 2002).

\section{MODELING POPULATION STRUCTURE AND HERD MANAGEMENT}

\section{Type of Herd}

One of the most important factors influencing Map transmission is whether it is a dairy or a beef farm. Contacts between animals differ between these 2 types of farm, as does transmission via calf feeding. In beef cow-calf herds, calves are raised in the same environment as their dam until at least 7 mo of age, whereas on most of the dairy farms, separation from adults occurs within a few hours or days after birth. Because of the higher susceptibility of young calves, raising calves with adults should strongly influence Map transmission. Moreover, beef cows often have a lower replacement rate than dairy cows, therefore tending to be older at culling. As a result, the chance for beef cows to reach an infectious stage is higher.

Three papers investigate disease dynamics in both dairy and beef herds [model 2, one associated paper analyzing this model (Groenendaal et al., 2003), and model 4]. However, in model 4, only replacement rate and herd size differ between the 2 types of herd; contact structures are the same for the 2 farm types in the model. Outputs of both models are different and thus cannot be directly compared. Adapting contact structure to that of a beef herd should account for both increased direct contacts between the dam and its calf before weaning and for indirect fecal-oral transmission through Map survival in the environment.

\section{Herd Management}

Contact Structure. In a farm, animals are often grouped by age or production status. Therefore, contacts between animals are not homogeneous within a herd. Animal locations influence both local bacterial density, especially when adults are considered, and probability of infection, especially when calves are considered. Allowing contacts between young stock and adults or even among young stock enhances Map transmission. Furthermore, calving management (i.e., seasonal calving versus year-round calving) influences the mixing 
of animals of different age groups; year-round calving increases the likelihood of raising calves of different age in the same pen (collective housing facility).

In the models, age of animals is always considered because it influences infection-related factors (e.g., susceptibility), but most often not because of preferential contacts between animals of the same age. Model 8 as an exception considers different contact rates whether animals are of the same age or not, assuming much greater intra-group than inter-group rates of contact. In this model, calf-to-calf transmission could therefore be higher than adult-to-calf transmission depending on the value of the parameter tested. Inter-class rate of contact appears to be always the same. In model 2, separation of age groups is modeled by a reduction of the contact rate $k$ in the formula (Table 3). No calf-tocalf transmission is possible (i.e., no specific intra-class rate of contact), but adult-to-calf transmission varies with the age of the calf (different inter-class rate of contact).

Models could be improved by including a more detailed contact structure between animals in a herd because contact structure may play a considerable role in pathogen transmission as has been shown for some other cattle diseases (Ezanno et al., 2008). The number of shedding animals, the type of housing facilities, and the management of the herd in terms of space utilization should therefore be taken into account.

Herd Size. In models 2 and 4, increasing herd size has been reported to increase the speed of the transmission and the infection prevalence at which equilibrium is reached, assuming a similar herd management. From model 4, the authors conclude that it is not possible to assess if this is linked to a greater risk of introducing infected animals into a larger herd, or if it is linked to different within-herd disease dynamics. On the contrary, in model 1, increasing herd size decreases the prevalence after the introduction of one infected animal. The authors explain this phenomenon by the increase in the number of susceptible animals in larger herds, in association with the decreased probability of effective contact. This finding contrasts with observed data from which the seroprevalence of paratuberculosis appears to be positively correlated to herd size (Wells and Wagner, 2000; Muskens et al., 2003).

Herd size is likely to influence the results when modeling Map transmission within a cattle herd. However, conclusions are still controversial. More precise information about the effect of herd size on within-herd infection levels would thus be useful while also taking account of transmission via the environment. Improving our knowledge about Map density, Map survival in the environment, and the role of fomites in Map spread within a herd is required to do so. Furthermore, results could differ depending on the transmission function used (Hoch et al., 2008). In a frequency-dependent model, the force of infection is indeed constant, whereas the number of infected animals increases with herd size in a density-dependent model, leading to the increase of the force of infection.

Control of Herd Size. Sales and culling can influence the spread of the pathogen in 2 contrasting ways. On the one hand, if the culling rate is higher than the renewal rate, farmers have to purchase animals to keep the herd size constant, which increases the risk of introducing infected animals. On the other hand, if the culling rate is low, infected but undetected animals remain in the herd and the chance to contaminate the environment increases.

In the selected models, either closed (models 4, 5, 6 , and 8) or open herds (models 1, 2, 3, and 7) are modeled. In open herds, purchased heifers are either assumed to be uninfected (model 4) and thus introduction does not contribute to Map spread, or infected (models 1,2 , and 7), resulting in maintaining Map in the herd. However, because of the low sensitivity of diagnostic tests, it is difficult to be certain that purchased animals are truly uninfected. Calves born to either infected or uninfected dams have the same probability to be kept in the herd unless there is an active intervention on the former (model 8). Culling due to paratuberculosis infection is infection stage-dependent (models $2,4,7$, and 8) or age-dependent (model 1) when represented. Model 1 assumes that there is no variation of the infection stage for a given age. This assumption is acceptable for a simple model but not truly realistic for paratuberculosis, knowing the variability of the incubation period. It is known, furthermore, that the culling rate of clinically affected animals is higher than for other stages of infection. This is taken into account in models $2,4,7$, and 8 . In these models, animals can become clinically diseased at any age.

Other Routes of Pathogen Introduction. In addition to the purchase of infected cattle, between-herd transmission occurs through transfers of feces, manure, slurry, soiled forage, and use of soiled fields for pasture, and thus is dependent on herd management. Pathogen introduction into a cattle herd can also originate from other farmed ruminants such as sheep and goats, or from wildlife (Beard et al., 2001; Manning, 2001; Daniels et al., 2003). However, the strain of Map isolates from wildlife has not been confirmed to be the same as in domestic ruminants (Daniels et al., 2003; Anderson et al., 2007). Furthermore, the causal link and the direction of potential causality between environmental contamination from wildlife or cattle and infection in cattle or wildlife are difficult to prove under field conditions mainly because of the long incubation period 
of the disease and the resulting difficulty of excluding other potential sources of infection (Daniels et al., 2003). Moreover, even if Map transfers were possible between wildlife and domestic cattle, under typical farm management conditions, the frequency of contacts between young susceptible animals and wildlife, or environments contaminated by wildlife, is low. This is particularly true on dairy farms where calves are kept indoors. Moreover, the contribution of wildlife is likely to be small once the disease becomes established in a herd compared with the challenge from infected cattle present within the same herd. None of the reviewed models consider other sources of infection but cattle.

\section{MODELING CONTROL OF MAP INFECTION}

One of the most important control measures is to prevent the exposure of young animals to Map. Both in utero transmission and ingestion of Map in feces, milk, or colostrum have to be controlled. The only possible control for in utero infection is to cull an infected cow that is likely to infect her fetus. After birth, protection of susceptible cattle implies hygienic measures such as preventing calf contamination by early separation from the dam, using milk and colostrum from noninfected dams, using milk replacer or pasteurized milk, calving in a separate pen, cleaning the calving pen, preventing contact between cattle of different ages, improving the general cleanliness of the cattle and housing, using noncontaminated feed, water, and pasture for rearing young cattle, and raising calves born from infected and noninfected cows separately (Gay and Sherman, 1992; Rossiter and Burhans, 1996).

Decreasing the number of infectious cattle in the herd to decrease contamination of the environment is an alternative to the control of exposure. Therefore, possible measures are to cull detectable infectious animals, to purchase animals in herds known to be clear of infection, to cull calves born from infected dams, or to reduce stressful events that trigger progression of the infection and shedding of Map (McKenna et al., 2006). Several test-and-cull strategies have been proposed, always accounting for the low sensitivity of diagnostic tests (Groenendaal et al., 2003). Furthermore, culling cattle positive to a culture-based test assumes that isolation of $M a p$ indicates established infection and not simple transit of Map through the gastrointestinal tract. It also assumes that recovery from infection cannot occur and that the culture-based tests are $100 \%$ specific (Sockett et al., 1992).

Vaccination is also possible to reduce the number of fecal shedders (Kormendy, 1994) and the number of clinically affected cattle in a herd (Wentink et al.,
1994). However, the vaccine has been prohibited in several countries such as Sweden, the United Kingdom, and Ireland because it interferes with diagnostic tests. Moreover, although vaccination reduces the economic losses of paratuberculosis (van Schaik et al., 1996), it does not reduce Map transmission (Kalis et al., 2001). Therefore, hygienic practices remain essential in herd management.

All these measures are more or less strictly applied depending on the constraints of the farms (such as housing facilities). Their effect on disease dynamics within a herd are not known in detail. The association between management-related risk factors and (apparent) prevalence of Map has been studied broadly, but these studies do not take into account the time between the implementation of the preventive measures and the disease dynamics (Obasanjo et al., 1997; Jakobsen et al., 2000; Dieguez et al., 2008).

A modeling approach is relevant for evaluating and comparing control strategies of Map spread in a cattle herd. Most reviewed models have been used for such a purpose, especially for evaluating test-and-cull options when diagnostic tests are poorly sensitive (Collins and Morgan, 1991a, 1992; Groenendaal and Galligan, 2003; Groenendaal et al., 2003; Dufour et al., 2004; Weber et al., 2004; Kudahl et al., 2007b, 2008; Weber et al., 2008). The only strategies predicting a decrease in prevalence are those including actions targeting infection routes (such as improved hygiene or improved milk feeding management); test-and-cull strategies alone (considering imperfect tests) have no or little effect on the prevalence (models 2 and 7 ). In model 2, the more management measures a farmer takes, the more effective a control program is. It is not possible to rank studied control measures according to their effectiveness because results of individual management control measures are not given. If tests had a sensitivity of 1 , the impact of a test-and-cull option would be more important. The reviewed models cannot be used to evaluate the effect of contact structure on Map transmission, because contact structure is not specifically represented. However, it could be of interest to know whether limiting indirect contacts between adults and calves or between calves would have an effect on Map transmission.

\section{MODEL VALIDATION}

Model validation is the step that assesses if the model accurately represents the real system. Qualitative or quantitative validation is performed by checking that appropriate assumptions have been made, by verifying that observed behaviors can be mimicked with the 
model, or by comparing model outputs with observed data. Validation is generally partial (Oreskes et al., 1994) as it is usually difficult to compare strictly similar situations. For example, it is rare to collect data for a situation without any control measure when it comes to paratuberculosis. To evaluate model behavior, a sensitivity analysis can be performed on uncertain variables. Sensitivity analysis aims to quantify how model outputs vary with a change in parameter values (Saltelli et al., 2000). Uncertain parameters strongly influencing model outputs are suitable targets for further research.

The consistency between model outputs and real system behavior was assessed for model 2 via the study of the transmission parameter. Model 2 simulates an overall transmission parameter similar to estimates from a field study (Groenendaal et al., 2002). Moreover, the results of a certification-and-surveillance scheme were comparable in outcomes of a simulation with model 2 and in a field study in 90 dairy herds (Weber et al., 2004). The small number of such comparisons is associated with the lack of comprehensive data about Map dynamics. The seasonal hypothesis (exposure differs between winter housing versus summer grazing) made in model 6 was examined against data collected for this purpose (Kudahl et al., 2007a). No effect of the season of calving was found in field data.

In 5 models $(2,4,6,7$, and 8), a sensitivity analysis is performed on uncertain parameters. Studied parameters related to exposure are bacterial survival rate, density of bacteria in the feces of shedding cattle, size of the infectious area (these 3 first parameters being studied in model 6), number of contacts to potentially infected cattle (models 7 and 8), and initial herd-level prevalence (one associated paper of model 2 analyzing this model: Weber et al., 2008). Model 6 appears to be highly sensitive to changes in bacterial density and to size of the exposure area. Other models are also sensitive to the parameters related to exposure they studied. Studied parameters related to transmission are pathogen transmission probability [model 2, one associated paper analyzing this model (Weber et al., 2008), and model 4], probability of introducing infected cattle [model 2 and one associated paper analyzing this model (Groenendaal et al., 2003)], and probability of infection (model 6). All models are sensitive to all the parameters related to the particular transmission mechanism they studied. Finally, studied parameters related to infection consequences are the probabilities of disease onset (models 2 and 4). Again, models are sensitive to all the parameters related to infection consequences they studied. The sensitivity analyses did not enable identification of any parameter related to Map transmission and consequences for which uncertainty has little effect on the model results.

\section{DISCUSSION}

The review has shown that the models described in the published literature are constrained by limitations of the epidemiological knowledge at the time of their development. The maximum age at which cattle can become infected and the dose-response relationship between the quantity of Map organisms and infection probability of cattle at different ages are currently unknown. Whether dose or age at infection has an influence on disease progression is also unknown. It should be kept in mind that the identification of important areas for future research is one of the purposes of modeling. Moreover, as new information becomes available, the disease processes implemented in these models can be represented more precisely and parameters can be more accurately defined. Effect of selective culling of the most susceptible calves or future supershedders can be studied when information on genetic susceptibility markers is available. However, complex models are not necessarily able to represent a biological system better than simpler ones. In summary, based on current knowledge, Map transmission could be more precisely modeled by including the recently described calf-to-calf transmission pathway, a more detailed contact structure between animals within a herd, and explicit incorporation of indirect transmission, representing Map transmission in the environment. Consequences of this improved precision on model accuracy would have to be investigated.

The number of compartments represented in the models varies. The compartments should reflect the pathogenesis of the disease; thus, susceptible, transiently infectious, latently infected, infectious, and resistant states should be represented. Moreover, clinically affected animals are specific infectious animals that all shed a high load of Map. In utero transmission is of greater risk for them and their probability of being culled is higher. Having a specific compartment thus seems essential. Other compartments could be added depending on the aim of modeling. For example, supershedders have been described and their role in the infection dynamics needs further investigation. Two modeling options could be used: either considering a large variability of shedding within the infectious compartment, with a small proportion of individuals shedding a very high amount of Map (to represent heterogeneity of shedding in time) or considering an extra compartment for supershedders, supershedders being considered as specific animals.

It is now acknowledged that calf-to-calf transmission occurs, albeit at a lower rate than adult-to-calf transmission. Furthermore, this newly acknowledged route of transmission appears to be necessary for Map persistence in the only published model that takes 
Table 5. Summary of assumptions incorporated in 8 Mycobacterium avium paratuberculosis (Map) transmission models in cattle herds (for assumptions on transmission, see Table 4)

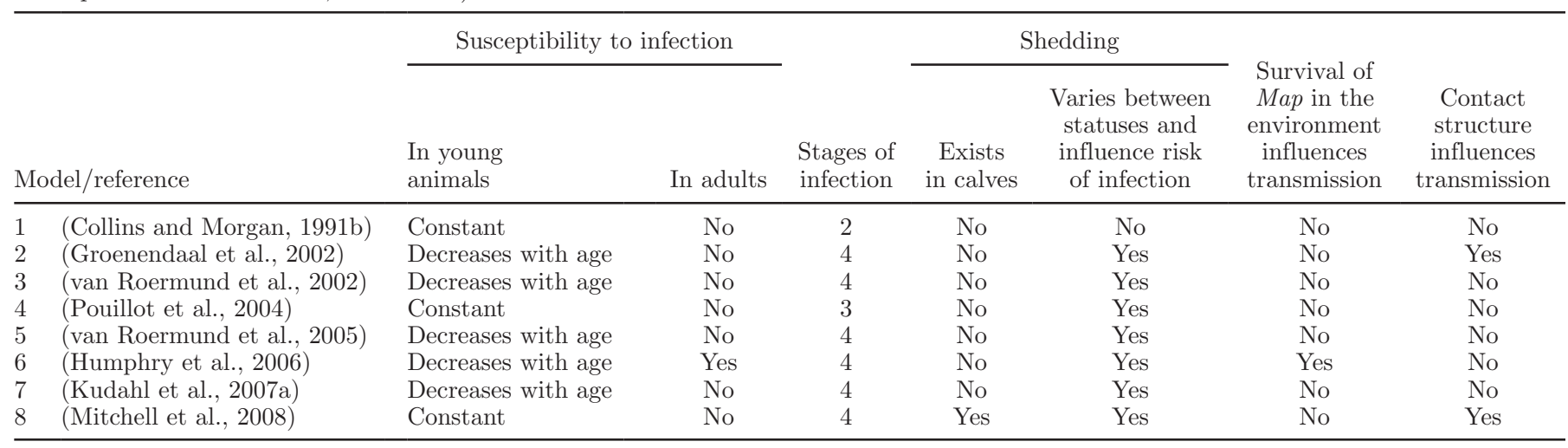

account of calf-to-calf transmission. However, little is known on calf-to-calf transmission rate or on the contribution of this route to total transmission in a herd. A study reported that in one herd, 9.5\% of the offspring of test-negative dams, not exposed to other positive cows in the calving pen, became infected (Benedictus et al., 2008). Overall, a risk of $6 \%$ was not explained by exposure to a positive dam, exposure in the calving area, or by being raised with a calf that later in life becomes a high shedder. The difference, $3.5 \%$, can be considered an estimate of the risk of becoming infected due to calf-to-calf transmission in this herd. Hence, it is important to develop models that evaluate whether calf-to-calf transmission might be an important critical point for controlling Map transmission.

In all published models, it is assumed that calves can become infected through several transmission routes during the susceptible period before the age of $1 \mathrm{yr}$. However, the relative importance of each route in $M a p$ infection dynamics within an infected herd is poorly understood. To assess more precisely the contribution of the different routes of transmission, the level of shedding has to be explicitly modeled. Moreover, to account for indirect milk and colostrum contamination by feces of the dam and the global contamination of the environment around birth, an overall infectiousness of the herd has to be considered. Information on the relative importance of each route of transmission is required for defining more cost-effective preventive measures because farmers are unlikely to implement management procedures that affect several mechanisms at the same time, but instead will need to prioritize their actions. Knowing the relative importance of each route of infection would allow balanced decisions in relation to the most cost-effective control measures.

Currently available models differ substantially in relation to their assumptions with respect to herd size, management, and structure (Table 5). The influence of these assumptions on the infection process is not known. Although 3 papers study the effect of herd size on model outputs, none studies the impact of calf-tocalf and adult-to-calf contacts. To determine which characteristics of the herd management or herd structure have to be accounted for in future modeling, one would need a model that enabled studying, one at a time, the effect of considering or not one option. Moreover, it is currently difficult to compare or characterize available models in terms of accuracy because baseline scenario (acting as the gold standard) and outputs of interest are missing or not reported. It is not currently possible to perform a model comparison in achieving maintenance of infection, given available data on published models. Future model simulation should produce outputs on Map persistence in a herd so that comparisons could be performed on critical features. The effect of contact structure on Map transmission has never or only partially been addressed. This would necessitate developing a new model. A definite conclusion on the need to complicate model structure is not currently possible, but neglecting the contact structure and ignoring transmission via the environment are likely to highly influence the model outputs. Direct contact between calves or sharing the same environment depends on the sub-grouping of animals of the same age and on their housing. When modeling calf-to-calf transmission via the environment, one should not forget to consider that calves shed less and produce less feces than adults.

Selecting a density- or frequency-dependent function of transmission can have an effect on the outputs (Hoch et al., 2008). The choice of the transmission function must be based on the biological knowledge on the modeled pathogen and host and on experimental data. It is difficult to select a priori one or the other function for paratuberculosis when indirect transmission is considered. However, the frequency-dependent function assumes that the occupied area is constant whatever the 
population size (Begon et al., 2002), which is usually not the case for the size of pens and farm facilities when the size of the herd increases. Therefore, a densitydependent function seems to better reflect exposure of susceptible animals.

Simplifications have been performed in all models in terms of detection of the different stages of infection. Test sensitivities applied for each model compartment are specified as constant in a time period, ignoring that intervals between tests are often long (and up to $1 \mathrm{yr}$ ). Using a constant sensitivity during $1 \mathrm{yr}$ is questionable because there are no data in the literature on test sensitivity when applied to up to 1 yr before the true status is known. It is thus probable that average sensitivities are overestimated in such models.

Adequate parameterization of models such as the ones reviewed here is often difficult, due to lack of data. Consequently, several parameters are highly uncertain, particularly those related to pathogen transmission and between-group rates of contact. Uncertainties can be evaluated through sensitivity analyses that determine which parameters have a strong influence on the results and thus should be studied in priority in future field research. The reviewed models have mainly been evaluated through a sensitivity analysis but only for a small number of parameters, and only one at a time. Only model 4 performed an analysis for several parameters simultaneously. A more systematic sensitivity analysis taking account of interactions between parameters and of all the unknown or uncertain parameters should be performed to determine where uncertainty must be reduced and to evaluate whether a model can be used as a predictive tool or to improve our understanding (Saltelli et al., 2000).

There is a need for new models that consider indirect transmission via the environment taking account of Map survival and contact structure between animals in a herd. Such models should provide outputs on persistence and relative importance of the routes of transmission to be able to provide critical features on the construction of future Map transmission models in terms of herd management and herd structure characteristics.

\section{ACKNOWLEDGMENTS}

The authors gratefully acknowledge Herman van Roermund (Central Veterinary Institute of Wageningen UR, Animal Sciences Group, Lelystad, the Netherlands) for his contribution to the tables, and Lisa Collins (Royal Veterinary College, Veterinary Epidemiology and Public Health Group, University of London, UK) and Anne-France Viet (INRA, ONIRIS, UMR1300 Bio- agression, Epidémiologie et Analyse de Risque, Nantes, France) for their advice regarding the manuscript.

\section{REFERENCES}

Anderson, J. L., J. K. Meece, J. J. Koziczkowski, D. L. Clark, R. P. Radcliff, C. A. Nolden, M. D. Samuel, and J. L. E. Ellingson. 2007. Mycobacterium avium ssp. paratuberculosis in scavenging mammals in Wisconsin. J. Wildl. Dis. 43:302-308.

Antognoli, M. C., H. L. Hirst, F. B. Garry, and M. D. Salman. 2007. Immune response to and faecal shedding of Mycobacterium avium ssp. paratuberculosis in young dairy calves, and the association between test results in the calves and the infection status of their dams. Zoonoses Public Health 54:152-159.

Beard, P. M., M. J. Daniels, D. Henderson, A. Pirie, K. Rudge, D Buxton, S. Rhind, A. Greig, M. R. Hutchings, I. McKendrick, K. Stevenson, and J. M. Sharp. 2001. Paratuberculosis infection of nonruminant wildlife in Scotland. J. Clin. Microbiol. 39:15171521

Begg, D. J., and R. J. Whittington. 2008. Experimental animal infection models for Johne's disease, an infectious enteropathy caused by Mycobacterium avium ssp. paratuberculosis. Vet. J. 176:129145.

Begon, M., M. Bennett, R. G. Bowers, N. P. French, S. M. Hazel, and J. Turner. 2002. A clarification of transmission terms in hostmicroparasite models: Numbers, densities and areas. Epidemiol. Infect. 129:147-153.

Benedictus, A., R. M. Mitchell, M. Linde-Widmann, R. Sweeney, T. Fyock, Y. H. Schukken, and R. H. Whitlock. 2008. Transmission parameters of Mycobacterium avium subspecies paratuberculosis infections in a dairy herd going through a control program. Prev. Vet. Med. 83:215-227.

Benedictus, G., A. A. Dijkhuizen, and J. Stelwagen. 1987. Economic losses due to paratuberculosis in dairy cattle. Vet. Rec. 121:142146.

Bolton, M. W., D. L. Grooms, and J. B. Kaneene. 2005. Fecal shedding of Mycobacterium avium ssp. paratuberculosis in calves: Implications for disease control and management. Pages 596-600 in Proc. 8th Int. Colloq. Paratuberculosis, Copenhagen, Denmark; http://pubs.paratuberculosis.org

Chiodini, R. J., H. J. Van Kruiningen, and R. S. Merkal. 1984. Ruminant paratuberculosis (Johne's disease): The current status and future prospects. Cornell Vet. 74:218-262.

Clarke, C. J. 1997. The pathology and pathogenesis of paratuberculosis in ruminants and other species. J. Comp. Pathol. 116:217-261.

Collins, M. T., and I. R. Morgan. 1991a. Economic decision analysis model of a paratuberculosis test and cull program. J. Am. Vet. Med. Assoc. 199:1724-1729.

Collins, M. T., and I. R. Morgan. 1991b. Epidemiological model of paratuberculosis in dairy cattle. Prev. Vet. Med. 11:131-146.

Collins, M. T., and I. R. Morgan. 1992. Simulation model of paratuberculosis control in a dairy herd. Prev. Vet. Med. 14:21-32.

Crossley, B. M., F. J. Zagmutt-Vergara, T. L. Fyock, R. H. Whitlock, and I. A. Gardner. 2005. Fecal shedding of Mycobacterium avium ssp. paratuberculosis by dairy cows. Vet. Microbiol. 107:257-263.

Daniels, M. J., M. R. Hutchings, P. M. Beard, D. Henderson, A. Greig, K. Stevenson, and J. M. Sharp. 2003. Do non-ruminant wildlife pose a risk of paratuberculosis to domestic livestock and vice versa in Scotland? J. Wildl. Dis. 39:10-15.

Dieguez, F. J., I. Arnaiz, M. L. Sanjuan, M. J. Vilar, and E. Yus. 2008. Management practices associated with Mycobacterium avium subspecies paratuberculosis infection and the effects of the infection on dairy herds. Vet. Rec. 162:614-617.

Dorshorst, N. C., M. T. Collins, and J. E. Lombard. 2006. Decision analysis model for paratuberculosis control in commercial dairy herds. Prev. Vet. Med. 75:92-122.

Doyle, T. M. 1953. Susceptibility to Johne's disease in relation to age. Vet. Rec. 65:363-364.

Dufour, B., R. Pouillot, and B. Durand. 2004. A cost/benefit study of paratuberculosis certification in French cattle herds. Vet. Res. 35:69-81. 
European Commission. 2000. Possible links between Crohn's disease and Paratuberculosis. Report of the Scientific Committee on Animal Health and Animal Welfare. 76 Pages. European Union, Brussels, Belgium.

Ezanno, P., C. Fourichon, and H. Seegers. 2008. Influence of herd structure and type of virus introduction on the spread of bovine viral diarrhoea virus (BVDV) on the spread of bovine viral diarrhoea virus (BVDV) within a dairy herd. Vet. Res. 39:39. doi:10.1051/vetres:2008016

Ezanno, P., G. van Schaik, M. F. Weber, and J. A. Heesterbeek. 2005. A modeling study on the sustainability of a certificationand-monitoring program for paratuberculosis in cattle. Vet. Res. $36: 811-826$.

Frank, D. N. 2008. Mycobacterium avium subspecies paratuberculosis and Crohn's disease. Lancet Infect. Dis. 8:345-346.

Gay, J. M., and D. M. Sherman. 1992. Factors in the epidemiology and control of ruminant paratuberculosis. Vet. Med. 87:1133-1139.

Gonda, M. G., Y. M. Chang, G. E. Shook, M. T. Collins, and B. W. Kirkpatrick. 2006. Genetic variation of Mycobacterium avium ssp. paratuberculosis infection in US Holsteins. J. Dairy Sci. 89:18041812.

Gonda, M. G., B. W. Kirkpatrick, G. E. Shook, and M. T. Collins. 2007. Identification of a QTL on BTA20 affecting susceptibility to Mycobacterium avium ssp. paratuberculosis infection in US Holsteins. Anim. Genet. 38:389-396.

Groenendaal, H., and D. T. Galligan. 2003. Economic consequences of control programs for paratuberculosis in midsize dairy farms in the United States. J. Am. Vet. Med. Assoc. 223:1757-1763.

Groenendaal, H., M. Nielen, and J. W. Hesselink. 2003. Development of the Dutch Johne's disease control program supported by a simulation model. Prev. Vet. Med. 60:69-90.

Groenendaal, H., M. Nielen, A. W. Jalvingh, S. H. Horst, D. T. Galligan, and J. W. Hesselink. 2002. A simulation of Johne's disease control. Prev. Vet. Med. 54:225-245.

Groenendaal, H., and F. J. Zagmutt. 2008. Scenario analysis of changes in consumption of dairy products caused by a hypothetical causal link between Mycobacterium avium subspecies paratuberculosis and Crohn's disease. J. Dairy Sci. 91:3245-3258.

Hagan, W. A. 1938. Age as a factor in susceptibility to Johne's disease. Cornell Vet. 28:34-40.

Hoch, T., C. Fourichon, A. F. Viet, and H. Seegers. 2008. Influence of the transmission function on a simulated pathogen spread within a population. Epidemiol. Infect. 136:1374-1382.

Humphry, R. W., A. W. Stott, C. Adams, and G. J. Gunn. 2006. A model of the relationship between the epidemiology of Johne's disease and the environment in suckler-beef herds. Vet. J. 172:432445 .

Jakobsen, M. B., L. Alban, and S. S. Nielsen. 2000. A cross-sectional study of paratuberculosis in 1155 Danish dairy cows. Prev. Vet. Med. 46:15-27.

Johnson-Ifearulundu, Y. J., and J. B. Kaneene. 1997. Epidemiology and economic impact of subclinical Johne's disease: A review. Vet. Bull. 67:437-447.

Kalis, C. H. J., M. T. Collins, H. W. Barkema, and J. W. Hesselink. 2004. Certification of herds as free of Mycobacterium paratuberculosis infection: Actual pooled faecal results versus certification model predictions. Prev. Vet. Med. 65:189-204.

Kalis, C. H. J., J. W. Hesselink, H. W. Barkema, and M. T. Collins. 2001. Use of long-term vaccination with a killed vaccine to prevent fecal shedding of Mycobacterium avium subsp. paratuberculosis in dairy herds. Am. J. Vet. Res. 62:270-274.

Koets, A. P., G. Adugna, L. L. G. Janss, W. H. J. Van, C. H. J. Kalis, G. H. Wentink, V. P. M. G. Rutten, and Y. H. Schukken. 2000. Genetic variation of susceptibility to Mycobacterium avium ssp. paratuberculosis infection in dairy cattle. J. Dairy Sci. 83:2702-2708.

Kormendy, B. 1994. The effect of vaccination on the prevalence of paratuberculosis in large dairy herds. Vet. Microbiol. 41:117125 .
Kostoulas, P., S. S. Nielsen, W. J. Browne, and L. Leontides. 2010. A Bayesian Weibull survival model for time to infection data measured with delay. Prev. Vet. Med. 94:191-201.

Kruip, T. A. M., J. Muskens, R. H. J. W. Van, D. Bakker, and N. Stockhofe-Zurwieden. 2003. Lack of association of Mycobacterium avium ssp. paratuberculosis with oocytes and embryos from moderate shedders of the pathogen. Theriogenology 59:1651-1660.

Kudahl, A. B., S. S. Nielsen, and S. Ostergaard. 2008. Economy, efficacy, and feasibility of a risk-based control program against paratuberculosis. J. Dairy Sci. 91:4599-4609.

Kudahl, A. B., S. Ostergaard, J. T. Sorensen, and S. S. Nielsen. 2007a. A stochastic model simulating paratuberculosis in a dairy herd. Prev. Vet. Med. 78:97-117.

Kudahl, A. B., J. T. Sorensen, S. S. Nielsen, and S. Ostergaard. 2007b. Simulated economic effects of improving the sensitivity of a diagnostic test in paratuberculosis control. Prev. Vet. Med. 78:118 129

Larsen, A. B., R. S. Merkal, and R. C. Cutlip. 1975. Age of cattle as related to resistance to infection with Mycobacterium paratuberculosis. Am. J. Vet. Res. 36:255-257.

Larsen, A. B., R. S. Merkal, and T. H. Vardaman. 1956. Survival time of Mycobacterium paratuberculosis. Am. J. Vet. Res. 17:549-551.

Lovell, R., M. Levi, and J. Francis. 1994. Studies on the survival of Johne's bacilli. J. Comp. Pathol. 54:120-129.

Lu, Z., R. M. Mitchell, R. L. Smith, J. S. Van Kessel, P. P. Chapagain, Y. H. Schukken, and Y. T. Grohn. 2008. The importance of culling in Johne's disease control. J. Theor. Biol. doi:10.1016/j. jtbi.2008.05.008.

Manning, E. J. 2001. Mycobacterium avium subspecies paratuberculosis: A review of current knowledge. J. Zoo Wildl. Med. 32:293-304.

McKenna, S. L. B., G. P. Keefe, A. Tiwari, J. VanLeeuwen, and H. W. Barkema. 2006. Johne's disease in Canada. Part II: Disease impacts, risk factors, and control programs for dairy producers. Can. Vet. J. 47:1089-1099.

Mitchell, R. M., R. H. Whitlock, S. M. Stehman, A. Benedictus, P. P. Chapagain, Y. T. Grohn, and Y. H. Schukken. 2008. Simulation modeling to evaluate the persistence of Mycobacterium avium ssp. paratuberculosis (MAP) on commercial dairy farms in the United States. Prev. Vet. Med. 83:360-380.

Mortensen, H., S. S. Nielsen, and P. Berg. 2004. Genetic variation and heritability of the antibody response to Mycobacterium avium ssp. paratuberculosis in Danish Holstein cows. J. Dairy Sci. $87: 2108-2113$.

Muskens, J., A. R. W. Elbers, W. H. J. Van, and J. P. T. M. Noordhuizen. 2003. Herd management practices associated with paratuberculosis seroprevalence in Dutch dairy herds. J. Vet. Med. B Infect. Dis. Vet. Public Health 50:372-377.

Nauta, M. J., and J. W. B. van der Giessen. 1998. Human exposure to Mycobacterium paratuberculosis via pasteurised milk: A modelling approach. Vet. Rec. 143:293-296.

Nielsen, S. S., and A. K. Ersboll. 2006. Age at occurrence of Mycobacterium avium subspecies paratuberculosis in naturally infected dairy cows. J. Dairy Sci. 89:4557-4566.

Obasanjo, I. O., Y. T. Gröhn, and H. O. Mohammed. 1997. Farm factors associated with the presence of Mycobacterium paratuberculosis infection in dairy herds on the New York State paratuberculosis control program. Prev. Vet. Med. 32:243-251.

Oreskes, N., K. Shrader-Frechette, and K. Belitz. 1994. Verification, validation, and confirmation of numerical models in the earth sciences. Science 263:641-646.

Pouillot, R., B. Dufour, and B. Durand. 2004. A deterministic and stochastic simulation model for intra-herd paratuberculosis transmission. Vet. Res. 35:53-68.

Rankin, J. D. 1961. The experimental infection of cattle with Mycobacterium johnei. III. Calves maintained in an infectious environment. J. Comp. Pathol. 71:10-15.

Rossiter, C. A., and W. S. Burhans. 1996. Farm-specific approach to paratuberculosis (Johne's disease) control. Vet. Clin. North Am. Food Anim. Pract. 12:383-415. 
Saltelli, A., K. A. Chan, and E. M. Scott. 2000. Sensitivity Analysis. John Wiley \& Sons, Ltd., Chichester, UK.

Shafran, I., and P. Burgunder. 2008. Potential pathogenic role of $M y-$ cobacterium avium subspecies paratuberculosis in Crohn's disease. Inflamm. Bowel Dis. 14:1753-1755. doi:10.1002/ibd.20513.

Smythe, R. H. 1950. Some observations on Johne's disease. Vet. Rec. $62: 429-438$.

Sockett, D. C., D. J. Carr, W. D. Richards, and M. T. Collins. 1992. A repository of specimens for comparison of diagnostic testing procedures for bovine paratuberculosis. J. Vet. Diagn. Invest. 4:188-191.

Streeter, R. N., G. F. Hoffsis, S. Bech-Nielsen, W. P. Shulaw, and M. Rings. 1995. Isolation of Mycobacterium paratuberculosis from colostrum and milk of subclinically infected cows. Am. J. Vet. Res. 56:1322-1324.

Sweeney, R. W., R. H. Whitlock, and A. E. Rosenberger. 1992a. Mycobacterium paratuberculosis cultured from milk and supramammary lymph nodes of infected asymptomatic cows. J. Clin. Microbiol. 30:166-171.

Sweeney, R. W., R. H. Whitlock, and A. E. Rosenberger. 1992b. Mycobacterium paratuberculosis isolated from fetuses of infected cows not manifesting signs of the disease. Am. J. Vet. Res. 53:477480 .

Tavornpanich, S., C. A. Munoz-Zanzi, S. J. Wells, E. A. Raizman, T. E. Carpenter, W. O. Johnson, and I. A. Gardner. 2008. Simulation model for evaluation of testing strategies for detection of paratuberculosis in Midwestern US dairy herds. Prev. Vet. Med. 83:65-82.

Taylor, A. W. 1953. Experimental Johne's disease in cattle. J. Comp. Pathol. 63:355-367.

Taylor, T. K., C. R. Wilks, and D. S. McQueen. 1981. Isolation of Mycobacterium paratuberculosis from the milk of a cow with Johne's disease. Vet. Rec. 109:532-533.

van Roermund, H. J. W., D. Bakker, P. T. J. Willemsen, and M. C. M. De Jong. 2007. Horizontal transmission of Mycobacterium avium ssp. paratuberculosis in cattle in an experimental setting: Calves can transmit the infection to other calves. Vet. Microbiol. 122:270-279.

van Roermund, H. J. W., and M. C. M. de Jong. 2002. Within-herd transmission of paratuberculosis and the possible role of infectious calves. Page 92 in Proc. 7th Int. Colloq. on Paratuberculosis, Bilbao, Spain; http://pubs.paratuberculosis.org

van Roermund, H. J. W., M. F. Weber, A. A. de Koeijer, A. G. J. Velthuis, and M. C. M. de Jong. 2005. Development of a milk quality assurance program for paratuberculosis: from within- and between-herd dynamics to economic decision analysis. Pages 51-59 in Proc. 8th Int. Colloq. Paratuberculosis, Copenhagen, Denmark; http://pubs.paratuberculosis.org

van Roermund, H. J. W., M. F. Weber, E. A. M. Graat, and M. C M. De Jong. 2002. Monitoring programmes for paratuberculosis- unsuspected cattle herds, based on quantification of between-herd transmission. Pages 371-375 in Proc. 7th Int. Colloq. Paratuberculosis, Bilbao, Spain; http://pubs.paratuberculosis.org

van Schaik, G., C. H. J. Kalis, G. Benedictus, A. A. Dijkhuizen, and R. B. M. Huirne. 1996. Cost-benefit analysis of vaccination against paratuberculosis in dairy cattle. Vet. Rec. 139:624-627.

Weber, M. F., H. Groenendaal, R. H. J. W. Van, and M. Nielen. 2004. Simulation of alternatives for the Dutch Johne's disease certification-and-monitoring program. Prev. Vet. Med. 62:1-17.

Weber, M. F., J. Kogut, J. de Bree, G. van Schaik, and M. Nielen. 2006. Survival analysis of age at onset of shedding of Mycobacterium avium ssp. paratuberculosis. Page 444 in Proc. 11th Symp. Int. Soc. Vet. Epidemiol. Econ. (ISVEE), Cairns, Australia.

Weber, M. F., M. Nielen, A. G. J. Velthuis, and H. J. W. van Roermund. 2008. Milk quality assurance for paratuberculosis: Simulation of within-herd infection dynamics and economics. Vet. Res. 39:12. doi:10.1051/vetres:2007050

Weber, M. F., J. Verhoeff, G. van Schaik, and C. van Maanen. 2009. Evaluation of Ziehl-Neelsen stained faecal smear and ELISA as tools for surveillance of clinical paratuberculosis in cattle in the Netherlands. Prev. Vet. Med. 92:256-266.

Wells, S. J., and B. A. Wagner. 2000. Herd-level risk factors for infection with mycobacterium paratuberculosis in US dairies and association between familiarity of the herd manager with the disease or prior diagnosis of the disease in that herd and use of preventive measures. J. Am. Vet. Med. Assoc. 216:1450-1457.

Wentink, G. H., J. H. Bongers, A. A. Zeeuwen, and F. H. Jaartsveld. 1994. Incidence of paratuberculosis after vaccination against $M$. paratuberculosis in two infected dairy herds. Zentrabl. Veterinärmed. B 41:517-522.

Whitlock, R. H., and C. Buergelt. 1996. Preclinical and clinical manifestations of paratuberculosis (including pathology). Vet. Clin. North Am. Food Anim. Pract. 12:345-356.

Whitlock, R. H., S. J. Wells, R. W. Sweeney, and J. Van Tiem. 2000. ELISA and fecal culture for paratuberculosis (Johne's disease): Sensitivity and specificity of each method. Vet. Microbiol. $77: 387-398$

Whittington, R. J., I. B. Marsh, and L. A. Reddacliff. 2005. Survival of Mycobacterium avium ssp. paratuberculosis in dam water and sediment. Appl. Environ. Microbiol. 71:5304-5308.

Whittington, R. J., D. J. Marshall, P. J. Nicholls, I. B. Marsh, and L. A. Reddacliff. 2004. Survival and dormancy of Mycobacterium avium ssp. paratuberculosis in the environment. Appl. Environ. Microbiol. 70:2989-3004.

Whittington, R. J., and P. A. Windsor. 2009. In utero infection of cattle with Mycobacterium avium ssp. paratuberculosis: A critical review and meta-analysis. Vet. J. 179:60-69.

Windsor, P. A., and R. J. Whittington. 2010. Evidence for age susceptibility of cattle to Johne's disease. Vet. J. 184:37-44 